\title{
Hubungan Pemijatan Bayi Oleh Ibu Dengan Kualitas Tidur Bayi Di Desa Banyuputih Kidul Kecamatan Jatiroto Kabupaten Lumajang
}

\author{
Aldi Febrian Wieminaty \\ Program Studi DIII Kebidanan Sekolah Tinggi Ilmu Kesehatan Bhakti Al-Qodiri \\ Email : opricelx@yahoo.com
}

\begin{abstract}
ABSTRAK
Pijat bayi adalah seni perawatan kesehatan dan pengobatan yang dikenal sejak awal manusia diciptakan di dunia serta telah dipraktekkan sejak berabad-abad tahun silam secara turun-temurun oleh dukun bayi. Yang disebut bayi adalah anak yang berumur 0-12 bulan.Di Wilayah Desa Banyuputih Kidul Kecamatan Jatiroto Kabupaten Lumajang, didapatkan dari 10 bayi terdapat 3 bayi yang tidak nyenyak atau terbangun saat tidur dan 7 bayi lainnya mengalami nyenyak saat tidur malam. oleh karena itu peneliti ingin mengetahui adakah hubungan antara bayi yang di pijat dan tidak dipijat dengan kualitas tidur bayi.

Jenis penelitian yang digunakan adalah penelitian experiment, pengambilan sampel dengan sistematik random sampling, sampel yang digunakan adalah bayi berusia 0-12 bulan di wilayah Desa Banyuputih Kidul sebanyak 36 bayi. Data dikumpulkan dengan cara menyebar kuesioner dan pengolahan data secara tabulasi dengan uji statistik Chi square.

Dari $50 \%$ ibu yang memijat bayinya di dapatkan $47,22 \%$ bayi yang tidur lelap dan $2,78 \%$ bayi yang tidur tidak lelap, dan dari $50 \%$ atau kelompok ibu yang tidak memijat bayinya didapatkan $5,56 \%$ bayi yang tidur lelap dan $44,44 \%$ bayi tidur tidak lelap.

Setelah dilakukan uji statistik chi-square didapatkan $\chi^{2}$ sebesar 21,854, sedangkan $\chi^{2}$ tabel chi-square dengan dk 1 sebesar 3,841 (21,854> nilai chi-square tabel 3,481), maka hipotesa nol (Ho) ditolak. Dan dilakukan uji koefisien kontingensi Hipotesis dengan hasil 0.641 , Nilai kekuatan hubungan $0,40<\mathrm{KK}<0,70$ Cukup berarti atau sedang.

Dari penelitian ini diharapkan para ibu untuk memijat bayinya dengan baik dan penuh kasih sayang pada bayinya.

Kata kunci : Pemijatan Bayi, Kualitas Tidur Bayi
\end{abstract}

\begin{abstract}
Baby massage is art of medical treatment and therapy than knowing along human created in this world and have been practiced last century by hereditarily with soothsayer. The baby is a child which the old age is 0-12 months. In the Village area of South District Banyuputih Jatiroto Lumajang, obtained from 10 infants there were three babies who do not sleep or waking during sleep and seven other babies have to sleep soundly at night. therefore, researchers want to know is there any relationship between infants in the massage and no massage with baby sleep quality.

Type of research is experiment, research, systematic sampling with random sampling, the sample was 0-12 months old infants in the Village area of South Banyuputih 36 infants. Data collected by questionnaire and data processing spread in tabulation with Chi square test.

Than $50 \%$ of mothers who massage their babies in a baby who got $47.22 \%$ and $2.78 \%$ sleeping babies do not sleep soundly, and from $50 \%$ or a group of mothers who did not massage the baby was found $5.56 \%$ of babies sleep soundly and $44,44 \%$ of infants do not sleep soundly.

After using the chi-square statistical test was found at 21.854, while the chi-square table with a $\mathrm{dk}$ of 3.841 (21.854> chi-square table value of 3.481), then the zero hypothesis (Ho) is rejected.
\end{abstract}


Contingency coefficient and hypothesis test with the results 0,641 , The strength of the relationship $0.40<$ KK $<0.70$ Fair means or medium.

Of this research is expected the mothers to massage their babies with a good and loving on her baby.

Keywords: Baby Massage, Baby Sleep Quality

\section{PENDAHULUAN}

Pijat bayi adalah seni perawatan kesehatan dan pengobatan yang dikenal sejak awal manusia diciptakan di dunia serta telah dipraktekkan sejak berabad-abad tahun silam secara turun-temurun oleh dukun bayi. Yang disebut bayi adalah anak yang berumur 0-12 bulan (Irmawati, 2015).

Keputusan Menteri Kesehatan Nomor 900/MENKES/SK/VII/2002 tentang Registrasi dan Praktek Bidan menyebutkan bahwa bidan berwenang memantau pertumbuhan dan perkembangan bayi melalui deteksi dini dan stimulasi tumbuh kembang. Salah satu bentuk stimulasi yang selama ini dilakukan oleh masyarakat adalah dengan pijat bayi (Roesli, 2009).

Pijat bayi merupakan tekhnik relaksasi yang diberikan pada usia bayi dan balita yang banyak memberi manfaat bagi anak. Pijat bayi dulu hanya dilakukan oleh dukun, namun sekarang dapat dilakukan oleh orang tua sendiri. (Irmawati, 2015).

Para ahli menyebutkan bahwa dengan tindakan pemijatan atau 'massage' dapat membantu bayi baru lahir tidur lebih nyenyak serta mengurangi kebiasaan bayi menangis. Pijat dikatakan mempunyai efek positif pada kesehatan bayi, karena berpengaruh terhadap kerja nervus vagus sehingga memperbaiki motilitas saluran cerna termasuk pengosongan lambung. Keadaan tersebut menyebabkan absorsi makanan dan kualitas tidur yang lebih baik. Penelitian ini bertujuan mengetahui efektifitas pijat bayi terhadap durasi tidur bayi (Galenia, 2014).

Seiring dengan perkembangan ilmu pengetahuan dan teknologi, para pakar telah membuktikan bahwa terapi sentuh dan pijat menghasilkan perubahan fisiologis yang menguntungkan berupa peningkatan pertumbuhan, peningkatan daya tahan tubuh, dan kecerdasan emosi yang lebih baik (Roesli, 2009).

Di Indonesia pelaksanaan pijat bayi di masyarakat desa masih dipegang peranannya oleh dukun bayi. Selama ini pemijatan tidak hanya dilakukan bila bayi sehat tetapi juga pada bayi sakit atau rewel dan sudah menjadi rutinitas perawatan bayi setelah lahir. Ilmu kesehatan modern telah membuktikan secara ilmiah bahwa terapi sentuhan dan pijat pada bayi mempunyai banyak manfaat terutama bila dilakukan sendiri oleh orang tua bayi Salah satunya adalah meningkatkan kosentrasi bayi dan membuat bayi tidur lebih lelap (Irmawati, 2015; Ameera, 2009).

Saat malam hari seringkali orang tua tidak dapat tidur dengan nyenyak karena bayinya sering terbangun pada tahun 20042005 di lima kota besar di Indonesia (Jakarta, Bandung, Medan, Palembang dan Batam), terdapat sebanyak $72,2 \%$ orang tua menganggap masalah tidur pada bayi bukan masalah atau hanya merupakan masalah kecil. Penelitian yang sama juga mengungkapkan, ada sekitar $44 \%$ balita yang mengalami gangguan tidur seperti sering terbangun di malam hari dan kurang tidur. Bayi dikatakan mengalami gangguan tidur jika pada malam hari tidurnya kurang dari 9 jam, terbangun lebih dari 3 kali dan lama terbangunnya lebih dari 1 jam. Selama tidur bayi terlihat selalu rewel, menangis dan sulit jatuh tidur kembali (Irmawati, 2015).

Jumlah bayi di Kabupaten Lumajang tahun 2009 adalah 16.369, dan pada tahun 
2010 adalah 16.060 dan jumlah bayi di Kecamatan Jatiroto tahun 2009 adalah 782, sedangkan jumlah bayi di tahun 2010 adalah 722, dan di Desa Banyuputih Kidul terdapat 72 bayi. Berdasarkan hasil pra survey yang telah dilakukan oleh penulis di Wilayah Desa Banyuputih Kidul Kecamatan Jatiroto Kabupaten Lumajang 2010, didapatkan dari 10 bayi terdapat 3 bayi (30\%) yang bayinya tidak nyenyak atau terbangun saat tidur dan 7 bayi lainnya mengalami nyenyak saat tidur malam.

Pijat bayi adalah seni perawatan kesehatan dan pengobatan yang dikenal sejak awal manusia diciptakan di dunia serta telah dipraktekkan sejak berabad-abad tahun silam secara turun-temurun oleh dukun bayi. Pemberian pijat pada bayi dapat meningkatkan durasi tidur pada bayi (Roesli 2009; Yazid, 2009).

Melihat hal tersebut diatas, penulis tertarik untuk mengetahui hubungan pemberian pijatan pada bayi dengan kualitas tidur bayi di Desa Banyuputih Kidul Kecamatan Jatiroto Kabupaten Lumajang.

\section{METODE PENELITIAN}

\section{Jenis dan Desain Penelitian}

Jenis penelitian yang digunakan adalah penelitian eksperimen, Dalam penelitian ini dimaksudkan untuk mengetahui hubungan pemijatan bayi oleh ibu dan kualitas tidur bayi di Desa Banyuputih Kidul Kecamatan Jatiroto Kabupaten Lumajang. Penelitian direncanakan berlangsung pada bulan April 2018 sampai Mei 2018. Pengumpulan data menggunakan kuisioner terstruktur yang telah diuji validitas dan reliabilitas sebelumnya dan lembar panduan observasi.

\section{Populasi dan Sampel}

Populasi

Populasi yang diamati peneliti dalam penelitian ini adalah bayi 0-12 bulan di Desa Banyuputih Kidul Kecamatan Jatiroto Kabupaten Lumajang, yaitu terdapat 72 bayi.

sampel yang peneliti gunakan adalah 36 bayi yang memenuhi syarat untuk dijadikan responden di Desa Banyuputih Kidul Kecamatan Jatiroto Kabupaten Lumajang,

\section{Variabel Penelitian}

Variabel bebas (Independent)

Adalah variabel yang nilainya menentukan variabel lain. Suatu kejadian stimulasi yang dimanipulasi oleh penelitian menciptakan dampak pada variabel terikat (Nursalam, 2008). Variabel bebas (independent) pada penelitian ini adalah pijat bayi .

Variabel terikat (dependent)

Adalah variabel yang nilainya ditentukan variabel lain. Faktor yang diambil dan diukur untuk menentukan ada tidaknya hubungan atau pengaruh dari variabel bebas (Nursalam, 2008).Variabel terikat (dependent) dalam penelitian ini adalah kualitas tidur bayi

HASIL PENELITIAN

Karakteristik Responden

\section{a. Karakteristik Berdasarkan Umur \\ Distribusi frekuensi responden berdasarkan umur dapat dilihat pada tabel:}

Tabel 1 Karakteristik Bayi Menurut Usia di Desa Banyuputih Kidul Kecamatan Jatiroto Kabupaten Lumajang Tahun 2018

\begin{tabular}{clcc}
\hline No. & $\begin{array}{c}\text { Usia } \\
\text { Bayi }\end{array}$ & Jumlah & $\begin{array}{c}\text { Persentase } \\
(\%)\end{array}$ \\
\hline 1 & $0-3$ & 5 & 13,89 \\
2 & $4-6$ & 11 & 30,55 \\
3 & $7-9$ & 10 & 27,78 \\
4 & $10-12$ & 10 & 27,78 \\
\hline \multicolumn{2}{c}{ Total } & 36 & 100 \\
\hline
\end{tabular}

Sumber : Data Primer 2018

Berdasarkan tabel 1 paling banyak adalah bayi berusia 4-6 bulan yaitu 11 orang $(27,78 \%)$ dan yang sedikit adalah bayi berusia $0-3$ bulan yaitu 5 orang $(13,89 \%)$.
b. Karakteristik
Berdasarkan Jenis Kelamin 
Distribusi frekuensi responden berdasarkan jenis kelamin dapat dilihat pada tabel dibawah ini :

Tabel 2 Karakteristik Bayi Menurut Jenis Kelamin di Desa Banyuputih Kidul Kecamatan Jatiroto Kabupaten Lumajang Tahun 2018

\begin{tabular}{cccc}
\hline No. & $\begin{array}{c}\text { Jenis } \\
\text { Kelamin } \\
\text { Bayi }\end{array}$ & Jumlah & $\begin{array}{c}\text { Persentase } \\
(\%)\end{array}$ \\
\hline 1 & Laki-laki & 18 & 50 \\
2 & Perempuan & 18 & 50 \\
\hline & Total & 36 & 100 \\
\hline
\end{tabular}

Sumber : Data Primer 2018

Berdasarkan tabel 4.2, 18 orang $(50 \%)$ bayi berjenis kalamin laki-laki, 18 orang $(50 \%)$ bayi berjenis kalamin perempuan.

\section{Data Khusus Responden}

Data khusus responden berisi tentang karakteristik yang ditanyakan kepada responden yang termasuk dalam variabel penelitian. Karakteristik yang dimaksud meliputi pemijatan bayi dan kualitas tidur bayi.

\section{c. Pemijatan bayi}

Tabel 3 Distribusi Frekuensi pemijatan bayi di wilayah Desa Banyuputih Kidul Kecamatan Jatiroto Kabupaten Lumajang Tahun 2018

\begin{tabular}{clcc}
\hline No & $\begin{array}{c}\text { Pemberian } \\
\text { pijatan }\end{array}$ & Frekuensi & $\begin{array}{c}\text { Persentase } \\
(\%)\end{array}$ \\
\hline 1 & Dipijat & 18 & 50 \\
2 & $\begin{array}{l}\text { Tidak } \\
\text { dipijat }\end{array}$ & 18 & 50 \\
\hline & Total & 36 & 100 \\
\hline
\end{tabular}

Sumber : Data Primer 2018

Dari tabel 3 didapatkan sebanyak 18 atau (50\%), bayi yang dipijat oleh ibu atau keluarganya dan 18 atau (50\%) bayi yang tidak dipijat oleh ibunya maupun keluarganya.

\section{d. Kualitas tidur bayi}

Tabel 4 Distribusi Frekuensi kualitas tidur bayi di wilayah Desa Banyuputih Kidul Kecamatan Jatiroto Kabupaten Lumajang Tahun 2018

\begin{tabular}{|c|c|c|c|}
\hline No. & $\begin{array}{c}\text { Kualitas } \\
\text { tidur }\end{array}$ & Frekuensi & $\begin{array}{l}\text { Persentase } \\
(\%)\end{array}$ \\
\hline 1 & Lelap & 21 & 58,33 \\
\hline 2 & $\begin{array}{l}\text { Tidak } \\
\text { lelap }\end{array}$ & 15 & 41,67 \\
\hline & Total & 36 & 100 \\
\hline & $\begin{array}{l}\text { mber: Da } \\
\text { Dari } \\
\text { anyak } 21 \\
33 \% \text { ) da } \\
\text { g tidur tic }\end{array}$ & $\begin{array}{l}\text { Primer } 2 \\
\text { abel } 4 \\
\text { bayi yans } \\
15 \text { di di } \\
\text { k lelap (4) }\end{array}$ & $\begin{array}{l}\text { idapatkan } \\
\text { dur lelap } \\
\text { tkan bayi } \\
7 \% \text { ). }\end{array}$ \\
\hline
\end{tabular}

e. Hubungan pemijatan bayi oleh ibu dan kualitas tidur bayi di wilayah Desa Banyuputih Kidul Kecamatan Jatiroto Kabupaten Lumajang Tahun 2018

Tabel 5 Tabel Silang Hubungan pemijatan bayi oleh ibu dan kualitas tidur bayi di wilayah Desa Banyuputih Kidul Kecamatan Jatiroto Kabupaten Lumajang Tahun 2018

\begin{tabular}{ccccccc}
\hline & \multicolumn{3}{c}{ Kualitas tidur bayi } & \multicolumn{2}{c}{ Total } \\
\cline { 2 - 7 } $\begin{array}{c}\text { Pemberia } \\
\text { n pijatan }\end{array}$ & \multicolumn{2}{c}{ Tidak Lelap } & \multicolumn{2}{c}{ lelap } & & \\
\cline { 2 - 7 } & Frek. & $\%$ & Frek. & $\%$ & $\begin{array}{c}\text { Fre } \\
\text { k. }\end{array}$ & $\%$ \\
\hline $\begin{array}{c}\text { Tidak } \\
\text { dipijat }\end{array}$ & 16 & 44,44 & 2 & 5,56 & 18 & 50 \\
\hline Dipijat & 1 & 2,78 & 17 & 47,22 & 18 & 50 \\
\hline Total & 19 & 47,22 & 17 & 52,78 & 36 & 100 \\
\hline
\end{tabular}

Sumber : Data Primer 2018

Untuk menghitung koefisien kontingensi (KK) terlebih dahulu menghitung nilai chi-square $\left(\chi^{2}\right)$, nilai $\chi^{2}$ dapat diperoleh bila sudah diketahui nilai frekuensi harapan (fh).

Tabel 6 Tabel Silang Frekuensi Harapan Hubungan pemijatan bayi oleh ibu dan kualitas tidur bayi di 


\section{wilayah Desa Banyuputih Kidul Kecamatan Jatiroto Kabupaten Lumajang Tahun 2018}

\begin{tabular}{lccc}
\hline \multirow{2}{*}{$\begin{array}{c}\text { Pemberian } \\
\text { pijatan }\end{array}$} & \multicolumn{2}{c}{$\begin{array}{c}\text { Kualitas tidur } \\
\text { bayi }\end{array}$} & \\
\cline { 2 - 3 } & Lelap & $\begin{array}{c}\text { Tidak } \\
\text { lelap }\end{array}$ & \\
\hline $\begin{array}{l}\text { Dipijat } \\
\text { Tidak } \\
\text { dipijat }\end{array}$ & 8,5 & 9,5 & 18 \\
\hline \multicolumn{1}{c}{ Total } & 8,5 & 9,5 & 18 \\
\hline
\end{tabular}

Sumber : Data Primer 2018

Rumus $\chi^{2}$ adalah sebagai berikut:

$\chi^{2}=\frac{\left.N((a+d)-(b+c))-\frac{1}{2} N\right)^{2}}{(a+b) \cdot(c+d) \cdot(a+c) \cdot(b+d)}$

$\chi^{2}=\frac{\left.36((16+17)-(2+1))-\frac{1}{2} 36\right)^{2}}{(18) \cdot(18) \cdot(17) \cdot(19)}$

$\chi^{2}=21,845$

Setelah dilakukan uji statistik chisquare dengan taraf signifikan 0,05 didapatkan $\chi^{2} \quad$ sebesar 21,854, sedangkan $\chi^{2}$ tabel chi-square dengan $\mathrm{dk}$ 1 sebesar 3,841. jadi didapatkan hasil $\chi^{2}$ hitung lebih besar dari $\chi^{2}$ tabel chisquare $(21,854>$ nilai chi-square tabel 3,481), maka hipotesa nol (Ho) ditolak da Ha diterima. Setelah dilakukan uji koefisien kontingensi, dengan rumus (rumus terlampir):

$$
\mathrm{KK}=\sqrt{\frac{21,845}{21,845+36}}
$$

$\mathrm{KK}=0,641$

Nilai kekuatan hubungan $0,40<$ $\mathrm{KK}<0,70$ Cukup berarti atau sedang. Hipotesis yang diambil adalah, pemijatan bayi berhubungan secara signifikan (Cukup berarti atau sedang) terhadap kualitas tidur bayi.

\section{PEMBAHASAN}

Pemberian pemijatan bayi yang dilakukan oleh ibu di Desa Banyuputih Kidul Kecamatan Jatiroto Kabupaten Lumajang.

Berdasarkan hasil penelitian yang dilakukan terhadap bayi yang diberi pijatan oleh ibu di Desa Banyuputih Kidul Kecamatan Jatiroto Kabupaten Lumajang Tahun 2018 didapatkan hasil penelitian tentang pemijatan bayi yang dilakukan oleh ibu yang mempunyai bayi. Terdapat 50\% ibu yang memijat bayinya dari jumlah keseluruhan 36 sampel ibu yang memiliki bayi. Dan ibu yang tidak memijat bayinya di Desa Bnyuputih Kidul berjumlah 50\% dari jumlah keseluruhan sampel, yang mana terdapat $36 \mathrm{ibu}$ yang memiliki bayi di Desa Banyuputih Kidul.

Pemijatan yang dilakukan oleh ibu biasanya di berikan pada saat sebelum mandi. Teori ini sesuai dengan hasil penelitian, dimana sebagian besar bayi dipijat oleh ibunya sendiri, karena ibu lebih percaya diri untuk memijat bayinya sendiri, selain mudah ibu juga dapat berintrogasi langsung dengan bayinya. Dan juga dalam pemijatan bayi terdapat tehnik bonding yaitu dimana ibu dan bayi bisa lebih dekat, hal ini sangat menguntungkan bagi ibu ataupun bayi karena pada saat ibu memberikan pijatan bayi juga selain mendapatkan kenyamanan juga mendapatkan rasa kasih sayang yang diberikan langsung oleh ibu melalui usapan lembut atau tekanan ringan ada tubuh bayi. Sebagian besar ibu memijat bayi dengan menggunakan minyak kayu putih ataupun minyak telon, karna sekaligus menambah rasa hangat pada tubuh bayi.

\section{Kualitas tidur bayi di Desa Banyuputih Kidul Kecamatan Jatiroto Kabupaten Lumajang. \\ Berdasarkan hasil penelitian, dari} kelompok bayi yang diberi pijatan diperoleh sebanyak $47,22 \%$ bayi yang tidur terlelap, dan $2,78 \%$ bayi yang tidak tidur terlelap. dan didapatkan $5,56 \%$ bayi dari kelompok bayi yang tidak dipijat mengalami tidur 
yang lelap, dan $44,44 \%$ bayi yang tidur tidak lelap.

Tidur adalah dimana seseorang merasa tidak sadar dalam beberapa waktu, dan kualitas tidur bayi diketahui dari kegiatan tidur pada bayi tersebut, dapat dinilai dari lama tidur bayi dan pada teori dikatakan tidur bayi yang baik (lelap) yaitu 14-18 jam sehari, dan terbangun lebih dari 3 kali.

Teori ini sesuai dengan hasil penelitian yang menunjukkan sebagian besar bayi yang di berikan pijatan oleh ibu atau keluarganya akan mengalami tidur yang lelap, yaitu akan tidur selama 14-18 jam sehari dan sedikit terbangun saat tidur, kurang dari 3 kali. Ibu mendapatkan cara pemijatan bayi dari penyuluhan tentang kualitas tidur bayi yang diberikan oleh peneliti.

Hubungan antara pemijatan bayi oleh ibu dan kualitas tidur bayi di wilayah Desa Banyuputih Kidul Kecamatan Jatiroto Kabupaten Lumajang.

pijat bayi berhubungan cukup berarti atau sedang terhadap kualitas tidur bayi. Dari $50 \%$ ibu yang memijat bayinya di dapatkan $47,22 \%$ bayi yang tidur lelap dan $2,78 \%$ bayi yang tidur tidak lelap, dan dari $50 \%$ atau kelompok ibu yang tidak memijat bayinya didapatkan $5,56 \%$ bayi yang tidur lelap dan 44,44\% bayi tidur tidak lelap.

Hal ini menunjukkan bahwa bayi yang mendapatkan pijatan dari ibunya akan dapat tidur terlelap karena otot bayi mendapatkan stimulus dari pijatan dengan tekanan ringan ataupun usapan dari ibunya.

Dan dari pengujian koefisian kontingensi (KK) didapatkan nilai 0,641. Menurut kriteria pengujian disimpulkan nilai 0,641 mempunyai kekuatan hubungan cukup berarti atau sedang

Pijat bayi adalah seni perawatan kesehatan dan pengobatan yang dikenal sejak awal manusia diciptakan di dunia serta telah dipraktekkan sejak dahulu secara temurun oleh dukun bayi. Yang disebut bayi adalah anak yang berumur 0-12 bulan. Bayi yang ototnya distimulus dengan urut atau pemijatan akan nyaman dan mengantuk. Kebanyakan bayi akan tidur dengan waktu yang lama begitu pemijatan usai dilakukan kepadannya. Selain lama bayi nampak tidur terlelap dan tidak rewel seperti sebelumnya. Hal ini menunjukkan bahwa bayi merasa tenang setelah dipijat. Ibu selalu merasa senang bila melihat bayinnya tidur lelap.

Jadi bayi akan dapat tidur lelap jika ia mendapatkan pijatan dari ibunya terutama, karna usapan dan tekanan ringan pada badan bayi akan membuat otot bayi terstimulus, dan menyebabkan bayi nyaman dan tenang, hal ini membuat bayi lelap saat tidur. Oleh karena itu perlu dikembangkan lagi secara luas tentang pijat bayi dan manfaatnya. Sehingga perlu adanya interaksi dan informasi tentang manfaat pijat bayi yang diberikan oleh tenaga kesehatan.

\section{PENUTUP \\ Kesimpulan}

Didapatkan sebanyak $50 \%$ bayi yang dipijat oleh ibu atau keluarganya di wilayah Desa Banyuputih Kidul Kecamatan Jatiroto kabupaten Lumajang dan 50\% bayi yang tidak dipijat oleh ibunya maupun keluarganya.

Bayi yang tidur terlelap di wilayah Desa Banyuputih Kidul Kecamatan Jatiroto Kabupaten Lumajang Tahun 2010 terdapat sebanyak $58,33 \%$ bayi dan tedapat $41,67 \%$ bayi yang tidak tidur terlelap.

Terdapat hubungan antara pemijatan bayi oleh ibu dengan kualitas tidur bayi di Desa Banyuputih Kecamatan Jatiroto kabupaten Lumajang, Nilai kekuatan hubungan 0,641 yang mana $0,40<\mathrm{KK}<$ 0,70 Cukup berarti atau sedang. Pemijatan bayi dapat meningkatkan kualitas tidur bayi.

\section{Saran Peneliti \\ Bagi Instansi Terkait}

Demi meningkatkan pembangunan sumber daya manusia yang berkualitas, diharapkan dapat meningkatkan penyuluhan tentang pemijatan bayi. yang di berikan oleh tenaga kesehatan dan khususnya bidan.

\section{Bagi Peneliti Lain}

Perlu penelitian lebih lanjut tentang hubungan pemijatan bayi dan kualitas tidur 
Vol. 11 No. 1, Juni 2019

bayi dengan mempertimbangkan

keterbatasan pada kami.

\section{Bagi Responden/ Masyarakat}

Meningkatkan informasi tentang pijat bayi, dan tentang kebutuhan istirahat tidur bayi. Serta menerapkan teknik bayi dengan baik dan penuh kasih sayang pada bayinya, dan hendaklah bertanya kepada tenaga kesehatan atau orang yang dianggap mampu tentang cara memijat bayi, jika kurang mengerti tentang tata cara memijat bayi

\section{DAFTAR PUSTAKA}

Irmawati. 2015. Bayi dan Balita Sehat. PT. Elexmedia Komputindo. Jakarta

Reoslie Utami. 2009. Pedoman Pijat Bayi.Pustaka Penmbangunan Swadaya Nusantara. Jakarta.

Galenia. 2014. Home Baby Spa. Penerbit plus. Jakarta

Ameera, Audra. Cara dan Tips Cerdas mengasuh Bayi. 2009. Sakti. Yogyakarta.

Notoadmodjo, S. 2012. Metodologi Penelitian Kesehatan. Jakarta, Rineka Cipta.

Nursalam, dan Siti Pariani. 2008. Pendekatan Praktis Metodelogi Riset Keperawatan, Jakarta, CV Sagung Seto.

Subekti, Yazid. 2009. Keajaiban Pijat Bayi dan Balita. Wahyu Media. Jakarta.

Hasan, Iqbal (2014), Analisis Data Penelitian Dengan Statistik, Jakarta : Bumi Aksara

Alimul, Aziz. 2011. Metode Penelitian Keperawatan dan Teknik Analisa Data. Salemba Medika. Jakarta.

Keputusan Menteri Kesehatan No. 900/MENKES/SK/VII/2002 tentang Registrasi dan Praktek Bidan 